\title{
A Second-Order Factor Gender-Measurement Invariance Analysis of Financial Exclusion in Ilorin, Nigeria
}

\author{
Adewale Abideen Adeyemi, Daud Mustafa, and Salami Luqman Oladipo
}

\begin{abstract}
This study examines a measurement invariance of a second-order factor models of financial exclusion among micro-entrepreneurs in Ilorin, Kwara State, Nigeria. Data elicited via a survey questionnaire was analysed using both the Statistical Package for Social Sciences (SPSS) 20.0 and Amos 20.0 software. The study revealed that financial exclusion as a second order factor is indicated by debt phobia, religion, financial complacency, and affordability and eligibility first order factors. Measurement invariance was tested based on gender via a set of hierarchically structured levels: a) configural invariance, b) metric invariance of both the firstorder and second-order models, $c$ ) intercepts of both the firstorder and second-order models, and d) residuals of both the first-order and second-order models. The groups were found to be invariant across the models. Moreover, based on t-test at alpha of 0.001 , the latent mean difference tests of the second order model indicates no statistically significant difference on a path by path basis along gender divides. This provides a further questioning on the focus on women of financial inclusion programmes.
\end{abstract}

Index Terms-Financial exclusion, measurement invariance, micro-entrepreneurs, second-order factor.

\section{INTRODUCTION}

Many development issues, especially persistent poverty resulting from inequalities in outcome and opportunities have been linked to financial exclusion [1] ${ }^{\mathrm{a}}$. Today, there are about 63 percent adults that lack access to formal financial services globally and majority of them live in the developing countries [2]. Also noted in the World [2] is the relative financial exclusion of females compared to males. Only 47 percent females have access to formal account globally. The scenario is even grave in the case of Sub Sahara Africa (SSA) where in the specific case of Nigeria, more than 70 percent lack access to formal account.Also, as noted by [3], only about 15 percent of the females in Nigeria have access to formal accounts. Given this financial exclusion situation in Nigeria and elsewhere, the World Bank, regional development banks, as well as the group of industrialised nations has recognised the benefits of financial inclusion for stability and integrity. ${ }^{\mathrm{b}}$ Most of these policy responses at improving financial citizenship are as

Manuscript received June 26, 2013; revised August 27, 2013.

Adewale Abideen Adeyemi is with International Islamic University, Malaysia (e-mail: abidewale@yahoo.com).

${ }^{a}$ Beck and De La Torre (2006) in their extensive literature review thus observed that empirical evidences abound relating both the depth and breadth of financial inclusiveness to economic development and poverty alleviation.

${ }^{\mathrm{b}}$ The G20 Summit in Pittsburgh, 2009; Toronto, June 2010; Seoul, November 2010; Cannes, 2011, and Los Cabos, 2012 have always addressed financial inclusion issues and policies. such, by default women-focused (Moon, 2009) ${ }^{c}$. This may be prejudicial to the likely possibility that financial exclusion may not be gender invariant. Policy and practical intervention may therefore, be floundered against the backdrop that in Africa particularly, the male is often the household head. When such males are inadvertently excluded on the basis of imported financial technologies alien to local socio-economic realities, policy counterproductivity such as persistent poverty may be inevitable.

As a follow up to [4], this paper aims to investigate the moderating effect of gender on the financial exclusion factors. This is by conducting a second-order measurement invariance analysis across a number of hierarchical models. The remaining of this paper is divided into: a brief literature review on the theory of imperfect market and financial exclusion, methodology, results, findings, and conclusion.

\section{LITERATURE REVIEW}

\section{A. Theory of Imperfect Market}

This theory, according to [5], derived from the seminal work of [6]. Its underlying assumption is that lenders avoid the incidence of adverse selection. This is so even when moral hazards remain a problem in the information asymmetry that they are faced with [7]. The formal financial institutions' profitability orientation deters them, for instance from lending to customers for whom they lack creditworthiness information. Usually, the poor borrowers often lack the requisite credit history to make them attract credit from the formal sources. They are either viewed as not bankable or creditworthy [8]. Therefore, the banks charge high interests in order to discriminate among; and have enough cover on their transaction with this group of borrowers [9], [10]. The moral hazard problem the lenders face is a reflection of their susceptibility to adverse selection of potential clients. ${ }^{\mathrm{d}}$ Even for other financial services such as savings, payments and remittances, insurance etc. on a micro basis, the operating costs vis-à-vis the economic benefits may be very colossal. The unavoidable consequence is that the lack of such 'bankization' of the marginal and/or core poor would further worsen the state of global financial exclusion.

\section{B. Financial Exclusion}

Financial exclusion may be viewed as the lack of access

c Most notable microfinance programmes for instance Grameen, Bangladesh Rehabilitation Assistance Committee (BRAC), Rural Development Scheme (RDS), Bank Rakyat Indonesia (BRI) etc.are targeted towards women.

${ }^{\mathrm{d}}$ Borrowers who access funds may still channel them into unproductive or uses at variance with the intention for which the credit was advanced thus affecting repayment ability. 
to and use of financial capital in its entire ramifications in a manner that is affordable and accessible [4]. This definition derives from the fact that there is often the mistaken assumption that access to financial resources implies usage [1]. Whereas, for instance, evidences abound that incidence of access without usage is quite pronounced in both the developed and developing countries [11]-[13]. The implication as noted in [14] is that such misconception may confound the outcome of financial inclusion policies and strategies.

Financial exclusion barriers have been variously classified by scholars such as [1], [4], [12], [14] and [15]. However, two broad categories have emerged from these studies vis. voluntary and involuntary financial exclusion barriers.

Reference [15] classified financial exclusion into price, informational, and product and service barrier factors. These factors reflect more of involuntary exclusion. The price factor relates to the unaffordability of the available financial services, while the informational factors relate to the information asymmetry archetypal of lending to those without adequate credit history and ratings. Given that the cost of rendering services to the poor is relatively high[16], the third factor relate to insufficient provision of the requisite financial services that the poor desire.

In their classification of financial exclusion, [12], [1] took cognizance of the voluntary financial exclusion barriers. In alignment with findings in other studies like [13] and [17], they concluded that religious considerations, phobia for debt, and previous negative experiences with financial institutions ${ }^{\mathrm{e}}$ etc significantly explains why people voluntarily exclude themselves from financial services. However, these studies also noted that factors like lending terms and conditions, geographical proximity, documentation complexities, procedural bureaucracy, collateral security requirement, and high financial charges etc significantly explain involuntary financial exclusion among people especially the poor. This is in addition to the findings in [18] and [19] that financial illiteracy or lack of awareness also explains involuntary financial exclusion.

Reference [14] further classified financial exclusion barriers into five. The first relates to access exclusion. This is reflected in financial institutions' reluctance to open branches in rural areas or inner cities. In some other instances the financial institutions open the branches to leverage on regulatory arbitrage as per deposit mobilization without commensurate lending opportunities to fund depositors. In some other instances branches are closed thus depriving residents of their financial citizenship. ${ }^{f}$

Reference [14] also noted condition exclusion and price exclusion as pertinent. The former relates to the very stringent eligibility criteria that borrowers need to satisfy to be eligible for financial credit for instance, while the latter denotes that quite often; such services are deliberately priced beyond the capabilities of the poor. The last two

${ }^{\mathrm{e}}$ Cultural distrusts for banks based on past experiences, or preference for privacy may make for a voluntary exclusion of some clients from usage of financial services (Osili and Paulson, 2006:22).

${ }^{\mathrm{f}}$ The failure of the formal banking system to offer a full range of depository and credit services, at competitive prices, to all households and/or businesses, especially the poor thus compromising their ability to participate fully in the economy and to accumulate wealth (Dymski, 2005:2) barriers noted in [14] are marketing exclusion and personal exclusion. The marketing exclusion derives from the clients targeting focus of the financial institutions. Apparently due to their commercial orientation, their entire marketing mix elements are not focused on the poor. Consequently, given any of or the combination of some or all the four factors above, some people may voluntarily exclude themselves from using financial services even when they have access.According to [19], this is the height of psychological response to systematic financial exclusion.

In the specific case of Nigeria, [4] based on a measurement model on same data set used in this study concluded that financial exclusion factors can be categorised into two vis. voluntary and involuntary. Eligibility and Affordability were the involuntary exclusion factors retained as awareness was dropped due to offending estimate. ${ }^{\mathrm{g}}$ The voluntary exclusion factors include religion, debt phobia, financial complacency, and cultural capital.

While studies on financial exclusion and its determining factors are many, there is a dearth of empirical studies on the moderating effect of certain demographic profiles on the measurement models obtained. In this case, a genderinvariance analysis is conducted in this study. This is due to two reasons. First is that most financial exclusion mitigating programmes are often deliberately targeted at women. This situation is similar in Nigeria. Secondly, ([14] pp. 570) noted the presence of deep discriminations in access to different groups. Most especially, between genders, and particularly women in Nigeria whom she stated are marginalized in many ramifications. As such, it becomes expedient in this study to conduct a second order hierarchical measurement invariance analysis based on gender divides. This is in the specific domain of financial exclusion determinants in the Nigerian context.

\section{Methodology}

The analysis in this study is based on primary data collected via a survey instrument. The instrument was developed by the author based on financial exclusion barrier issues raised in the extant literature. Out of 450 questionnaires distributed to micro-entrepreneurs in the sample $^{\mathrm{h}}, 302$ (67 percent) were duly completed and on which further analysis was conducted ${ }^{\mathrm{i}}$. The data elicited relate to the demographic profile of the respondents and the financial exclusion barriers that they are faced with. The data cleaning, exploratory factor analysis, first-order confirmatory factor analysis, tests for reliability, convergent validity and divergent validity were carried out. Results are already reported in ([2] pp. 9). All required threshold for model fit were met. As such, the statistical analysis conducted in this paper is a second-order gender invariance measurement model analysis using AMoS 20 software. In

\footnotetext{
${ }^{\mathrm{g}} \mathrm{A}$ direct path coefficient or regression coefficient with a value greater than 1.00. This is considered unacceptable in an SEM analysis.

${ }^{\mathrm{h}}$ This is based on convenience sampling as no sampling frame exist even though the micro-entrepreneurs maintain an ubiquitous presence in the study area.

${ }^{\mathrm{i}}$ Some of the cases deleted had missing data. The data in this instance was missing completely at random (MCAR). As suggested by Hair et al (2006), any remedy for missing data could be used. However, given sufficient sample size for the SEM, the authors preferred to exclude affected cases from further analysis.
} 
this case, given the model fit of the first-order financial exclusion model, a configural invariance analysis was carried out. Thereafter, metric invariance tests based on factor, intercepts, and residuals were conducted for the first and second order models. Given that the invariance tests were not statistically significant at the model level; a latent mean difference test was also carried out to test for differences based on path by path analysis.

\section{A. Second Order Factor Model}

An invariance analysis is used to test the equivalence of measured constructs across two or more groups, in this case gender based on males and females grouping. As mentioned in Chen, Sousa, and West (2005), there are increasing interests in testing for measurement invariance. However, they mentioned that most studies rarely conduct second order invariance analysis. The few studies that attempted did not go beyond examining a covariance structure. As part of their recommendation and following [20]-[23] measurement invariance in this study was done using the full mean and covariance structures. ${ }^{j}$

The advantages of doing a second-order factor analysis are numerous. For instance, it results in a more parsimonious model in which case fewer parameters are used to test the hypothesis that a higher order factor represents the pattern of relations among the first order factors [21]. Moreover, a theoretically error free estimates of the specific factors are obtained by separating unique variance of the first order factors from measurement errors. Also, complex measurement structures are easily interpretable via a second order measurement model [21].

\section{RESUlTS}

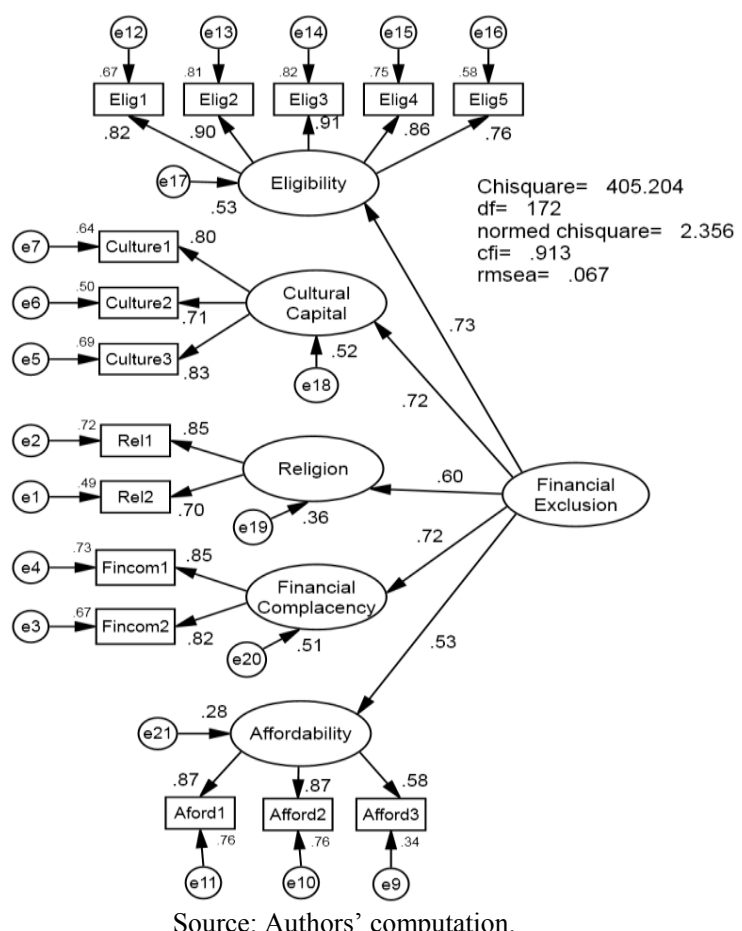

Fig. 1. Second order measurement model group 1- male).

\footnotetext{
${ }^{\mathrm{j}}$ The applicability of second order model in this study meets the assumption of an existing higher order factor model with four or more first order factors(Chen, Sousa, and West, 2005)
}

Based on the normed chi-square test score and the two fit indices - Comparative Fit Index (CFI) and Root Mean Square Error of Approximation (RMSEA) ${ }^{\mathrm{k}}$ in Fig. 1 and Fig. 2 above, the model fits the data. These indices as stated in [21] are used in the event of poor fit of a model based on significant $\mathrm{p}$-values that results in a large sample chi-square test.

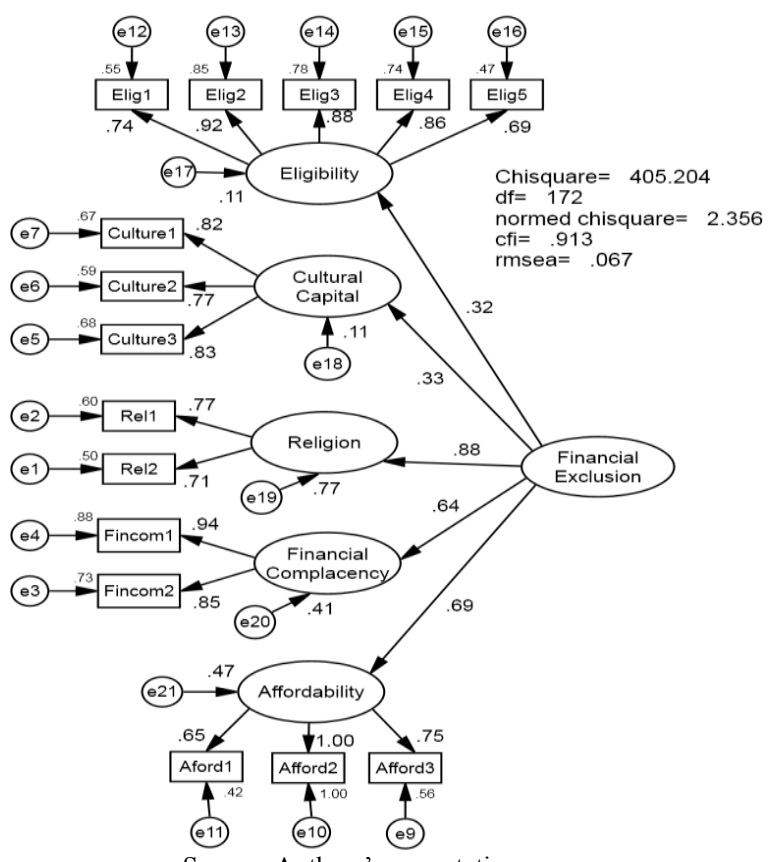

Source: Authors' computation.

Fig. 2. Second Order Measurement Model Group 1- Female).

A series of hierarchical measurement models nested within the baseline configural model $1^{1}$ was used to test for gender measurement invariance. The models 2 to 4 in both the first order and second order factor model invariance represent varying levels of constraints. For each of the nested model, a likelihood ratio test for differences was carried out based on changes in chi-square test scores and changes in degree of freedom.

In the model 1 in both the first and second order factor models, similar measurement model was tested along gender divide allowing parameters to be freely estimated. The results as shown in Table I and Table II indicate that the model fits the data and that the model is invariant across gender.

TABLE I: FIRST ORDER MODEL INVARIANCE

\begin{tabular}{|l|l|l|l|l|}
\hline Model & Model 1 & Model 2 & Model 3 & Model 4 \\
\hline$\chi^{2}$ & 349.6 & 360.0 & 385.4 & 431.1 \\
\hline DF & 188 & 199 & 214 & 230 \\
\hline RMSEA & 0.054 & 0.050 & 0.052 & 0.054 \\
\hline CFI & 0.94 & 0.94 & 0.94 & 0.93 \\
\hline$\Delta \chi^{2}$ & NA & 10.4 & 35.8 & 85.5 \\
\hline$\Delta$ DF & NA & 11 & 26 & 42 \\
\hline Sig. Level & NA & 0.001 & 0.001 & 0.001 \\
\hline Invariant? & YES & YES & YES & NO \\
\hline
\end{tabular}

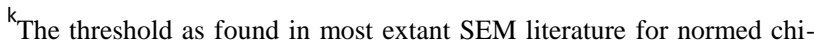
square is between 1 and 5, while those of the CFI and RMSEA are 0.90 and 0.08 respectively.

I The configural model allows the parameters across gender groups in the model to be freely estimated and tested for goodness of fit.
} 
TABLE II: SECOND ORDER MODEL INVARIANCE

\begin{tabular}{|l|l|l|l|l|}
\hline Model & Model 1 & Model 2 & Model 3 & Model 4 \\
\hline$\chi^{2}$ & 461.1 & 461.1 & 491.1 & 491.7 \\
\hline DF & 198 & 209 & 213 & 214 \\
\hline RMSEA & 0.067 & 0.065 & 0.066 & 0.065 \\
\hline CFI & 0.94 & 0.90 & 0.90 & 0.90 \\
\hline$\Delta \chi^{2}$ & NA & 15.1 & 30.0 & 26.7 \\
\hline$\Delta$ DF & NA & 32 & 15 & 16 \\
\hline Sig. Level & NA & 0.001 & 0.001 & 0.001 \\
\hline Invariant? & YES & YES & YES & YES \\
\hline
\end{tabular}

The model 2 tests for factorial invariance. In this case, although the baseline model had similar structure for both male and female grouping, all the first order and second order factor loadings were constrained. This procedure was followed in both the first order and second order measurement models respectively. The results indicate adequate fit of the models but invariant across gender divides as shown in Table I and Table II above.

Model 3 is further nested within the baseline first order and second order factor models but with additional constraint. In this case and across both factor models, the structural weights were also constrained to be equal among males and females. The results also indicate that the model fits the data based on the normed chi-square and fit indices. However, the test of measurement invariance indicates no statistical significance along gender divides.

In the Model 4, a similar baseline model structure was maintained for both males and females. However, a further constraint was added to the nested model 4 . In this case, added to the measurement weights and structural weights, the intercepts in both the first and second order model were constrained. While the first order model indicates a statistically significant moderating effect of gender, the second order model showed otherwise.

\section{FINDINGS AND CONCLUSION}

This paper demonstrated and applied the approach of testing for a second order measurement invariance of financial exclusion. The paper contend that compared to the first order factor model, the second order model with the first order factors as indicators is more parsimonious and provides theoretically error-free estimates of both the general and specific factors.

The combination of the measurement, structural, and intercept invariances of both the first and second order models indicate that factors that influence financial exclusion in Ilorin, Nigeria can be broadly categorised into voluntary and involuntary divides. While religious factors, cultural capital, and financial complacency account for the former, the latter is indicated by eligibility and affordability. These results were consistent with those found in previous studies like [1], [4], [12], [14] and [15].

The moderating effect of gender on financial exclusion in Ilorin, Nigeria is not statistically significant. This is contrary to expectation especially against the incipient argument by many studies and institutional data that the females are more financially excluded in Nigeria. ${ }^{\mathrm{m}}$ As such, it may be posited that while feminization of financial exclusion enjoys apparent appeal among policy makers, it may result in floundering policy outcome to presuppose masculinization of financial inclusion in Nigeria and elsewhere.

\section{REFERENCES}

[1] A. Demirguc-Kunt, T. Beck, and P. Honohan. (2008). Finance for all: Policies and pitfalls in expanding access. A World Bank Policy Research Report. [Online]. Available: http://www.worldbank.org

[2] World Bank Global Financial Inclusion Index. (2011). [Online]. Available: http://datatopics.worldbank.org/financialinclusion/

[3] J. Isern, A. Agbakoba, M. Flaming, J. Mantilla, G Pellegrini, and M. Tarazi, Access to Finance in Nigeria: Microfinance, Branchless Banking, and SME Finance, CGAP, 2009.

[4] A. A. Adewale, A. H. Pramanik, and A. K. MydinMeera, "A measurement model of the determinants of financial exclusion among muslim micro-entrepreneurs in Ilorin,Nigeria," Journal of Islamic Finance, vol. 1, no. 1, pp. 30-43, 2012

[5] P. Koveos, "Financial services for the poor: assessing microfinance institutions," Microfinance, vol. 30, no. 9, pp. 70-95. 2004.

[6] J. Stiglitz and A. Weiss, "Credit rationing in markets with imperfect information," American Economic Review, vol. 71, no. 3, pp. 393 410, 1981 .

[7] M. Nissanke and E. Aryeetey, Financial Integration and Development. Liberalization and Reform in Sub-Sahara Africa, London: Routledge, 1996.

[8] A. Adera, "Instituting effective linkages between formal and informal financial sector in Africa: A proposal," Savings and Development, vol. 1,1995

[9] N.A. Berger, L. F. Klapper, and G. F. Udell, "The ability of banks to lend to informational opaque small businesses," Journal of Banking and Finance, vol. 25, pp. 1-47, 2001.

[10] G. A. Dymski, "Financial globalization, social exclusion, and financial crisis," International Journal of Applied Economics, vol. 19, no. 4, pp. 439-457, 2005.

[11] A. Wallace and D. Quilgars, Homelessness and Financial Exclusion: A literature Review, Centre for Housing Policy, New-York, 2005.

[12] C. Corr, "Financial exclusion in ireland: an exploratory study and policy review," Combat Poverty Agency Research Series, no. 39, 2006

[13] A. A. Adewale, "Poverty alleviation through microenterprise development and access to microcredit. a case of households in the inner city of ilorin metropolis," presented at the $2^{\text {nd }}$ National Conference on Nigeria and Beyond 2007: Issues, Challenges and Prospects, University of Ilorin, Ilorin, Kwara State, Nigeria, February, 2007.

[14] A. Leyshon. (2009). Financial exclusion. International Encyclopaedia of Human Geography. [Online]. Available: andrewleyshon.files.wordpress.com/2007/11/financialexclusion_iehg_final-draft.pdf

[15] P. Honohan, "Financial development, growth and poverty: how close are the links?" in Financial Development and Economic Growth: Explaining the Links, Charles Goodhart, Ed. London: Palgrave, 2004, pp. 1-37.

[16] A. Isaksson, "The importance of informal finance in kenyan manufacturing," SIN Working Paper Series, Working Paper No. 5, 2002.

[17] U. O. Osili and A. Paulson. (2006). What can we learn about financial access from U.S. immigrants? [Online]. Available: http://www.chi.frb.org

[18] S. I. Owualah, "Do Nigerian SMEs face equity or credit finance gap?" Nigerian Economic Summit Group Economic Indicators, Lagos: NESG., 2002

[19] T. Beck and A. D. L. Torre, "The basic analytics of access to financial services," Financial Markets, Institutions, and Instruments, vol. 16, no. 2, pp. 79-117. 2007.

[20] E. Amali, "Gender and reform: the effects of reforms in the industrial sector on the economic empowerment of women,"in Nigeria's Reform Programme: Issues and Challenges, H. Saliu, E. Amali, and R. Olawepo, Eds. Ibadan, Nigeria: Vantage Publishers, 2007, pp. 569596.

[21] F. F. Chen, H. K. Sousa, and S. G. West, "Testing measurement invariance of second-order factor models," Structural Equation Modeling, vol. 12, no. 3, pp. 471-492, 2005.

\footnotetext{
${ }^{\mathrm{m}}$ See Isernet al. (2009), Amali (2007)
} 
[22] K. F. Widaman and S. P. Reise, "Exploring the measurement invariance of psychological instruments: applications in the substance use domain," In The Science of Prevention: Methodological Advances from Alcohol and Substance Abuse Research, K. J. Bryant, M. Windle, and S. G. West, Eds. Washington D.C.: American Psychological Association, 1997, pp. 281-324.

[23] W. Meredith, "Measurement invariance, factor analysis and factorial invariance," Psychometrika, vol. 58, pp. 525-543, 1993.

Adewale Abideen Adeyemi is an assistant professor of finance, Kulliyyah of Economics and Management Sciences, International Islamic University Malaysia. His research interests cover a wide range of areas in finance particularly development finance. His present researches are focused on microfinance, financial inclusion, and complementary currency.

Mustafa Daud is an academic staff in the Department of Economics, Faculty of Business and Social Sciences, University of Ilorin, Kwara State, Nigeria. His research interests are in the area of Development Economics. He has published extensively in this area.

Salami Lukman Oladipo is a professional accountant. In addition to ACCA, and MBA, he is also a doctoral candidate in Accounting. 